\title{
Can desalinated seawater contribute to iodine-deficiency disorders? An observation and hypothesis
}

\author{
Yaniv S Ovadia ${ }^{1,2}$, Dov Gefel ${ }^{1,2}$, Dorit Aharoni ${ }^{3}$, Svetlana Turkot ${ }^{4}$, Shlomo Fytlovich ${ }^{3}$ \\ and Aron M Troen ${ }^{1, *}$ \\ ${ }^{1}$ Nutrition and Brain Health Laboratory, School of Nutrition Science, Institute of Biochemistry, Food Science and \\ Nutrition, Robert H. Smith Faculty of Agriculture, Food and Environment, The Hebrew University of Jerusalem, PO Box \\ 12, Rehovot 76100, Israel: '2Department of Internal Medicine ' $C$ ', Barzilai University Medical Center Ashkelon, \\ Ashkelon, Israel: ${ }^{3}$ Laboratory of Clinical Biochemistry, Barzilai University Medical Center Ashkelon, Ashkelon, Israel: \\ ${ }^{4}$ Endocrinology Clinic, Barzilai University Medical Center Ashkelon, Ashkelon, Israel
}

Submitted 14 February 2016: Accepted 31 March 2016: First published online 6 May 2016

\begin{abstract}
Objective: Over 300 million people rely on desalinated seawater and the numbers are growing. Desalination removes iodine from water and could increase the risk of iodine-deficiency disorders (IDD). The present study assessed the relationship between iodine intake and thyroid function in an area reliant on desalination.

Design: A case-control study was performed between March 2012 and March 2014. Thyroid function was rigorously assessed by clinical examination, ultrasound and blood tests, including serum thyroglobulin ( $\mathrm{Tg}$ ) and autoimmune antibodies. Iodine intake and the contribution made by unfiltered tap water were estimated by FFQ. The contribution of drinking-water to iodine intake was modelled using three iodine concentrations: likely, worst-case and best-case scenario.

Setting: The setting for the study was a hospital located on the southern Israeli Mediterranean coast.

Subjects: Adult volunteers ( $n$ 102), 21-80 years old, prospectively recruited.

Results: After screening, seventy-four participants met the inclusion criteria. Thirty-seven were euthyroid controls. Among those with thyroid dysfunction, twenty-nine were classified with non-autoimmune thyroid disease (NATD) after excluding eight cases with autoimmunity. Seventy per cent of all participants had iodine intake below the Estimated Average Requirement (EAR) of $95 \mu \mathrm{g} / \mathrm{d}$. Participants with NATD were significantly more likely to have probable IDD with intake below the EAR $(\mathrm{OR}=5 \cdot 2 ; 95 \%$ CI 1.8, 15.2) and abnormal serum $\mathrm{Tg}>40 \mathrm{ng} / \mathrm{ml}(\mathrm{OR}=5 \cdot 8 ; 95 \%$ CI 1.6, 20.8).

Conclusions: Evidence of prevalent probable IDD in a population reliant on desalinated seawater supports the urgent need to probe the impact of desalinated water on thyroid health in Israel and elsewhere.
\end{abstract}

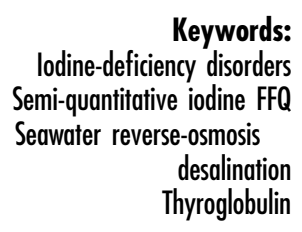

Chronically insufficient iodine intake may lead to disorders of the thyroid collectively called iodine-deficiency disorders (IDD) ${ }^{(1-5)}$. IDD cause impaired mental function, reduced work productivity, hyperthyroidism, and hypothyroidism in moderate-to-severe iodine deficiency and goitre, including irreversible non-toxic nodular goitre $(N N G)^{(5-7)}$. Pregnant women, the developing fetus and children are particularly vulnerable to the effects of iodine deficiency ${ }^{(1,5)}$. An estimated 2 billion people worldwide are at risk of $\operatorname{IDD}^{(1,4)}$. The problem is not limited to the developing world: about $50 \%$ of Europe's population remains mildly iodine deficient, and iodine intakes have fallen in recent years in other industrialized countries including the USA and Australia ${ }^{(5)}$. National public health programmes that include routine monitoring of iodine intake and universal salt iodization are the recognized standard for preventing $\operatorname{IDD}^{(4)}$. Such continuous monitoring of the sources and intake of dietary iodine, especially with increased desalination, are crucial to identify changes in iodine intake and prevent attendant health problems.

In some regions, the concentration of iodine in a population's water supply is an important determinant of intake $^{(8)}$. If the concentration is high enough, unfiltered 
drinking-water can provide a substantial proportion of the daily requirement ${ }^{(9)}$. Iodine in water also contributes to food iodine content through agricultural dairy and crop production $^{(10)}$.

With surging population growth and water scarcity worldwide, seawater desalination is increasingly used to meet increased demand for water ${ }^{(11)}$. Over 17000 desalination plants in 150 countries produce more than 80 million cubic metres of water per day for over 300 million people ${ }^{(12)}$. In the process, desalination typically removes almost all of the water's iodine ${ }^{(13)}$. Thus, theoretically, increased reliance on desalination could contribute to an increase in IDD.

Israel is a world leader in seawater desalination. Some of the world's largest seawater reverse-osmosis (SWRO) desalination plants, constructed along Israel's Mediterranean coast, now supply a growing proportion of Israel's drinking and irrigation water ${ }^{(14)}$. The desalinated water is supplied through a national water network that includes a seasonally varied mix of water from two other main sources: (i) the National Water Carrier that conveys surface water from the Sea of Galilee, a freshwater lake in the north, to the central and southern regions; and (ii) a system of wells that tap into underground aquifers and are fed locally into regional and municipal water works ${ }^{(15)}$. A smaller amount of desalinated brackish water and treated wastewater is also used for agriculture ${ }^{(16-18)}$.

Between 2008 and 2015 SWRO capacity increased by over $400 \%$ from 140 million cubic metres to 585 million cubic metres, and production is planned to exceed 800 million cubic metres by $2020^{(14)}$. At present, desalination provides approximately one-third of Israel's total water supply and up to half of its drinking-water overall ${ }^{(14)}$, and $85-99 \%$ of drinking-water in some municipalities (Y Kasperuk, Israel's Southern Region Water Supply Engineer, Mekorot Israel National Water Co., personal communication, 7 April 2014). Since SWRO typically removes $90-98 \%$ of soluble minerals, including iodine, from seawater ${ }^{(19)}$, the increased proportion of desalinated water used by consumers suggests that drinking-water will contribute significantly less to iodine intake in the population.

Current data for iodine concentration in drinking-water in Israel are unavailable. In the absence of such an overview, the case of Ashkelon may be instructive. In 2003, tap water in Ashkelon came from the national water carrier and local wells with an estimated weighted average concentration of $52 \mu \mathrm{g} / \mathrm{l}^{(20)}$. In 2005 the Ashkelon desalination plant began supplying desalinated water to the Ashkelon District water network and beyond ${ }^{(21,22)}$. A 2008 survey of tap water iodine content conducted by the Public Health Service of the Ministry of Health found an average concentration of $27 \mu \mathrm{g} / \mathrm{l}^{(23)}$. Since then the proportion of SWRO desalinated water in Ashkelon's supply has increased to $\sim 60 \%$ (Y Kasperuk, personal communication, 7 April 2014), predicting a further decrease in tap water iodine concentration ${ }^{(14)}$.
There is scant information on iodine status and IDD in Israel to relate to these data, as Israel is one of the few countries that has no salt iodization policy ${ }^{(24)}$ and has never conducted a national iodine intake survey ${ }^{(25)}$. It is assumed that about $3 \%$ of the table salt produced in Israel is iodized ${ }^{(24)}$. However, unpublished results from the first and second Israeli National Health Interview Surveys, INHIS-1 (2003-2004) and INHIS-2 (2007-2010) conducted by the Israel Center for Disease Control (ICDC), show that between 2003 and 2010 the self-reported use of thyroid medication among Israeli adults increased by $63 \%$ from 29 to 47 per 1000 adults (ICDC, personal communication, 2013). The causes of this apparent rise in prevalent thyroid disease have not been established; however, it is concurrent with the increased reliance on iodine-poor desalinated seawater. Given the growing use of SWRO desalination for drinking-water around the world ${ }^{(12,26)}$, investigating the possibility that the resulting reduction in available iodine may be contributing to increased incidence of IDD has both local and global significance. We therefore compared the prevalence of poor iodine intake in a case-control study of Israeli adults who use desalinated seawater and probably harbour IDD, and modelled the contribution of drinking-water to iodine intake.

\section{Materials and methods}

\section{Design, settings and participants}

The research protocol was approved by the medical ethics committee of Barzilai University Medical Center Ashkelon (BUMCA). All participants provided written informed consent after the research protocols were explained to them in detail.

Volunteers were prospectively recruited from inpatients and outpatients attending the BUMCA between March 2012 and March 2014. Recruitment, inclusion, exclusion and data collection were described previously in an earlier report on a subset of this population that focused on iodine intake and $\mathrm{NNG}^{(27)}$. Briefly, volunteers were classified as cases or controls, after their medical files were carefully screened, and all were interviewed using a structured sociodemographic, health and habits questionnaire. Only volunteers who had not changed their address or iodine intake habits during the 2 years prior to initiating the study were included. Moreover, patients were included only if their first diagnosis of any thyroid disease, according to either self-report or medical file, was made less than 5 years prior to the study. All participants with suspected thyroid disease underwent both ultrasound and fine-needle aspiration biopsy examinations. Volunteers with any autoimmune disease other than autoimmune thyroid disease (AITD) were excluded, as were those with a BMI of $<18.5$ or $>35.0 \mathrm{~kg} / \mathrm{m}^{2}$, those currently using iodine-containing or steroidal drugs, those with past or current cancer diagnosis and those currently pregnant. 
Table 1 Diagnostic criteria for thyroid diseases

\begin{tabular}{|c|c|}
\hline Thyroid disease type & Diagnostic criteria \\
\hline \multicolumn{2}{|c|}{ Non-autoimmune thyroid disease (NATD) } \\
\hline \multicolumn{2}{|c|}{ Non-toxic nodular goitre (NNG) } \\
\hline Single nodule & Goitre with nodule $>5 \mathrm{~mm}$ in diameter, TSH within the normal range ${ }^{*}$ \\
\hline Multiple nodules & Two or more nodules $>5 \mathrm{~mm}$ in diameter, TSH within the normal range* \\
\hline \multicolumn{2}{|r|}{ 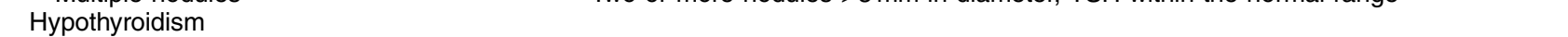 } \\
\hline Overt & $\mathrm{TSH}>4 \mathrm{mlU} / \mathrm{l}, \mathrm{FT}_{4}<0.8 \mathrm{ng} / \mathrm{dl}$ \\
\hline Subclinical & $\mathrm{TSH}>4 \mathrm{mlU} / \mathrm{l}, \mathrm{FT}_{4}$ within the normal range* \\
\hline \multicolumn{2}{|l|}{ Hyperthyroidism } \\
\hline Overt & $\mathrm{TSH}<0.4 \mathrm{mlU} / \mathrm{l}, \mathrm{FT}_{4}>1.8 \mathrm{ng} / \mathrm{dl}$ \\
\hline Subclinical & $\mathrm{TSH}<0.4 \mathrm{mlU} / \mathrm{l}, \mathrm{FT}_{4}$ within the normal range ${ }^{*}$ \\
\hline \multicolumn{2}{|c|}{ Autoimmune thyroid disease (AITD) } \\
\hline Hashimoto thyroiditis & Overt or subclinical hypothyroidism, TPOAb $>35 \mathrm{IU} / \mathrm{ml}$ (with or without nodular goitre) \\
\hline Graves' disease & Overt hyperthyroidism, TPOAb $>35 \mathrm{IU} / \mathrm{ml}$ (with or without diffuse goitret) \\
\hline
\end{tabular}

$\mathrm{TSH}$, thyrotropin; $\mathrm{FT}_{4}$, free thyroxine; TPOAb, thyroid peroxidase antibody.

*The reference range for TSH is $0.4-4.0 \mathrm{mIU} / \mathrm{l}$ and for $\mathrm{FT}_{4}$ is $0.8-1.8 \mathrm{ng} / \mathrm{dl}$; to convert values for $\mathrm{FT}_{4}$ from $\mathrm{ng} / \mathrm{dl}$ to $\mathrm{pmol} / \mathrm{l}$, $\mathrm{multiply}$ by 12.87 . †Diffuse goitre $=$ thyroid volume $>19.4 \mathrm{ml}$ (women) or $>25.6 \mathrm{ml}$ (men) without nodules.

Diagnostic criteria for all thyroid conditions included in the present study are listed in Table 1. Patients with Hashimoto thyroiditis and Graves' disease were classified as having AITD. After excluding patients with AITD, patients with untreated NNG, hyperthyroidism and hypothyroidism were classified as harbouring non-autoimmune thyroid disease (NATD). For NNG, each nodule was diagnosed as benign according to the fine-needle aspiration biopsy report. Blood drawn for determination of serum thyroglobulin (Tg) was taken at least 2 weeks after this procedure. Notably, the exposure variables of estimated dietary iodine intake and serum Tg were not used to classify participants as NATD.

\section{Risk factors for thyroid disease}

Each participant was interviewed about risk factors for thyroid disease including selected daily dietary goitrogen exposure (pine nuts, almonds, millet, linseeds, sorghum, sweet potato, cabbage, kale, cauliflower, broccoli), daily alcohol consumption ${ }^{(28)}$, previous X-ray examinations involving the jaw or neck area, post-psychological stressful event, use of thyroid-disrupting medication, family history of thyroid disease, current smoking habits and menopause (for women).

\section{Semi-quantitative iodine FFQ}

Habitual dietary iodine intake was estimated by a semiquantitative iodine FFQ (sIFFQ) that was adapted and translated from the only questionnaire that was validated before the current research was conducted ${ }^{(29,30)}$. This questionnaire was modified for use in Israel (see online supplementary material). In this sIFFQ, saltwater fish included all tuna, canned sardines, cooked or smoked salmon, cooked sea bream, grouper, red mullet, cod, halibut, cooked or salted mackerel and cooked or salted herring; seafood included any cooked or broiled crab, any cooked or broiled oyster, any cooked or grilled prawn and any cooked or grilled shrimp; milk included any cow's milk; tap drinking-water included any unfiltered tap water consumed via glasses, bottles, soups, coffee and tea.

To model the contribution of drinking-water to daily iodine intake, we assigned three values for water iodide concentration: (i) a value of $27 \mu \mathrm{g} / \mathrm{l}$, according to the calculated mean of fifty-one tap water samples taken from eighteen different locations throughout the Ashkelon District water network in a survey of iodide in drinkingwater conducted during November and December of 2008 by the Department of Environmental Health, Public Health Service at the Ministry of Health ${ }^{(23)}$; (ii) a worst-case scenario where tap water was derived only from SWRO desalinated water and assigned a value of $1 \mu \mathrm{g} / \mathrm{l}$ according to water samples taken from an Israeli SWRO desalination plant in $2003^{(9)}$ and in BUMCA (located less than $5 \mathrm{~km}$ north of Ashkelon desalination plant, its main water supplier) in 2015; and (iii) a best-case scenario where tap water was derived only from groundwater, assigning a value of $170 \mu \mathrm{g} / \mathrm{l}$ based on water samples taken from an active well, located about $40 \mathrm{~km}$ north of Ashkelon in the Ramla District ${ }^{(9)}$, that contains the highest iodide concentration recorded in Israel since the early 1980s and well above the national average ${ }^{(8,9)}$.

\section{Assays}

Serum values of free thyroxine ( $\left.\mathrm{FT}_{4}\right)$, thyrotropin (TSH), thyroid peroxidase antibody (TPOAb), thyroglobulin antibody (TgAb) and Tg were measured for all participants by the BUMCA Laboratory of Clinical Biochemistry using the IMMULITE 2000 analyser (Siemens Healthcare Diagnostics, Llanberis, UK) as previously described ${ }^{(27)}$. Serum $\mathrm{Tg}$ is a sensitive but non-specific candidate biomarker of iodine deficiency that increases in direct relation to the severity of deficiency, as well as in other conditions ${ }^{(31,32)}$. Although there is no consensus cut-off value for adults ${ }^{(33)}$, in previous population studies serum $\mathrm{Tg}$ concentrations of 
$10 \mathrm{ng} / \mathrm{ml}^{(32)}$ and values above $40 \mathrm{ng} / \mathrm{ml}$ were considered abnormal $^{(34,35)}$, and indicative in both cases of insufficient iodine intake. Hence, serum Tg values were explored as a biomarker of iodine status in the present study. Serum Tg was detectable in the serum of all but one participant (undetectable value at a range of $0-1 \mathrm{ng} / \mathrm{ml}$ ) to whom an arbitrary $1 \mathrm{ng} / \mathrm{ml}$ serum Tg concentration was assigned for statistical analysis. Participants positive for TgAb ( $>40 \mathrm{IU} /$ $\mathrm{ml})^{(34,35)}$, which would invalidate the attribution of elevated Tg to probable iodine deficiency, were excluded. Values of TPOAb above $35 \mathrm{IU} / \mathrm{ml}$ were considered positive $^{(34,35)}$. Ranges for normal thyroid tests were TSH of $0.4-4 \mathrm{mIU} / 1$ and $\mathrm{FT}_{4}$ of $0 \cdot 8-1.8 \mathrm{ng} / \mathrm{dl}$, according to the National Academy of Clinical Biochemistry ${ }^{(35)}$.

\section{Statistical analysis}

Descriptive statistics and statistical analyses were performed with JMP Pro software (version 10). Sociodemographic factors, risk factors for thyroid disease and serum $\mathrm{Tg}$ values were compared by group using the $\chi^{2}$ test, followed by Fisher's exact test. Goodness-of-fit for the distribution of estimated iodine intakes and serum Tg values in the complete study sample was determined by the Shapiro-Wilk $W$ and Cramer-von Mises $W$ test, respectively. Group means for demographic variables, iodine intake and log-transformed serum $\mathrm{Tg}$ were compared by one-way ANOVA with Tukey-Kramer honest significant difference, Welch's ANOVA and Kruskal-Wallis tests as appropriate. Serum $\mathrm{Tg}$ values were $\log$ transformed before analysis in order to normalize distribution. Geometric means of serum $\mathrm{Tg}$ values were calculated on back-transformed data.

The relationship between iodine intake and status to thyroid function was determined by comparing the proportion of controls and patients harbouring NATD with the following exposures: (i) intake below the RDA for nonpregnant adults $(150 \mu \mathrm{g} / \mathrm{d})$; (ii) intake below the Estimated Average Requirement (EAR; $95 \mu \mathrm{g} / \mathrm{d})^{(36)}$; (iii) use of iodized salt; (iv) elevated serum $\mathrm{Tg}(>10 \mathrm{ng} / \mathrm{ml})$; and (v) abnormal elevated serum $\mathrm{Tg}(>40 \mathrm{ng} / \mathrm{ml})$. Chi-square tests were performed, followed by Fisher's exact test and calculation of the odds ratio. The association of intake and $\log$-transformed $\mathrm{Tg}$ was determined by linear regression. A two-tailed $P$ value of $<0.05$ was considered statistically significant.

\section{Results}

\section{Participants}

Of 102 volunteers screened, seventy-four met the inclusion criteria (sixty women and fourteen men aged 21-80 years). Of these, thirty-seven were classified as euthyroid controls with no past or present thyroid disease; eight were diagnosed with AITD (seven with Hashimoto thyroiditis and one with Graves' disease); and twenty-nine were classified with NATD (seventeen harbouring euthyroid NNG, seven hypothyroid and four hyperthyroid participants). After excluding autoimmunity and other alternative risk factors, the most likely cause for thyroid dysfunction in these participants was iodine deficiency.

The sociodemographic characteristics of the three groups are shown in Table 2 . They did not differ significantly with respect to age, gender, ethnicity or prevalence of most thyroid disease risk factors. However, the prevalence of post-psychological stressful event and prior use of thyroiddisrupting medication was significantly higher in the AITD group compared with the other two $(P<0 \cdot 05)$.

Table 2 Sociodemographic characteristics and risk factors for thyroid disease in the study population of volunteers aged 21-80 years, Ashkelon, Israel, March 2012-March 2014

\begin{tabular}{|c|c|c|c|c|c|c|c|}
\hline \multirow[b]{2}{*}{ Characteristic } & \multicolumn{2}{|c|}{ Control } & \multicolumn{2}{|c|}{ AITD } & \multicolumn{2}{|c|}{ NATD } & \multirow[b]{2}{*}{$P$} \\
\hline & Mean or $n$ & SD or $\%$ & Mean or $n$ & SD or $\%$ & Mean or $n$ & SD or $\%$ & \\
\hline$n$ & \multicolumn{2}{|c|}{37} & \multicolumn{2}{|c|}{8} & \multicolumn{2}{|c|}{29} & \\
\hline Gender, $n$ (women, men) & \multicolumn{2}{|c|}{30,7} & \multicolumn{2}{|c|}{8,0} & \multicolumn{2}{|c|}{22,7} & \\
\hline \multicolumn{8}{|l|}{ Age (years) } \\
\hline Mean and SD & $56 \cdot 3$ & $13 \cdot 6$ & 53.4 & $13 \cdot 4$ & $57 \cdot 2$ & $13 \cdot 8$ & NS \\
\hline Range & \multicolumn{2}{|c|}{$23 \cdot 0-77 \cdot 0$} & \multicolumn{2}{|c|}{$29 \cdot 0-70 \cdot 0$} & \multicolumn{2}{|c|}{$21 \cdot 0-80.0$} & \\
\hline Israeli born, $n$ and \% & 13 & 35 & 5 & 63 & 7 & 24 & NS \\
\hline Nationality, $n$ (Jewish, other) & \multicolumn{2}{|c|}{36,1} & \multicolumn{2}{|c|}{8,0} & \multicolumn{2}{|c|}{29,0} & \\
\hline Tertiary education, $n$ and $\%$ & 11 & 30 & 4 & 50 & 13 & 45 & NS \\
\hline \multicolumn{8}{|c|}{ Possible risk factors for thyroid disease, $n$ and $\%$} \\
\hline Daily dietary goitrogen exposure & 11 & 30 & 1 & 11 & 6 & 21 & NS \\
\hline Daily excessive alcohol consumption & 0 & 0 & 0 & 0 & 0 & 0 & NS \\
\hline Previous X-ray examinations & 16 & 43 & 5 & 56 & 12 & 43 & NS \\
\hline Post-psychological stressful event* & 9 & 24 & 6 & 67 & 8 & 29 & $<0.05$ \\
\hline Prior use of thyroid-disrupting medication* & 2 & 5 & 3 & 33 & 1 & 4 & $<0.05$ \\
\hline Family history of thyroid disease & 8 & 22 & 2 & 22 & 6 & 21 & NS \\
\hline Current smoking habits & 10 & 27 & 2 & 22 & 7 & 25 & NS \\
\hline Menopause (for women) & 26 & 87 & 7 & 88 & 16 & 73 & NS \\
\hline
\end{tabular}

AITD, autoimmune thyroid disease; NATD, non-autoimmune thyroid disease.

*Significant difference (Fisher's exact test, $a=0.05$ ). 
Given the sociodemographic similarity of the groups, we first determined the distribution of iodine intake and status in our population, as estimated by SIFFQ and serum Tg. We then analysed whether intake and status were worse in the NATD group than in controls, as would be expected. Finally, we estimated the contribution of unfiltered tap drinking-water to iodine intake, assuming various scenarios of water iodine concentration.

\section{Estimated iodine intake, unfiltered tap water consumption and dietary babits by semi- quantitative iodine $F F Q$}

Overall, the mean estimated intake of unfiltered tap water was 0.7 litres/d, contributing $11 \mu \mathrm{g} / \mathrm{d}(13 \%)$ to the total daily iodine intake, when water iodine concentration was assigned the value of $27 \mu \mathrm{g} / \mathrm{l}$ according to the last measured data from $2008^{(23)}$. Accordingly, the median estimated dietary iodine intake for all participants was $84 \mu \mathrm{g} / \mathrm{d}$, with a mean of 93 (sD 51) $\mu \mathrm{g} / \mathrm{d}$ (Fig. 1(a)). The majority of the population, $87 \%$ of the participants, had intake below the RDA and $58 \%$ had intake below the $\mathrm{EAR}^{(36)}$. Insufficient iodine intake was high among controls, with a mean of 113 (SD 58) $\mu \mathrm{g} / \mathrm{d}$. Seventy-eight per cent of controls had intake below the RDA and $41 \%$ had intake below the EAR. Deficiency in the NATD group was significantly higher, with a mean iodine intake of 72 (SD 35) $\mu \mathrm{g} / \mathrm{d}$. In this group, $97 \%$ were below the RDA and $76 \%$ were below the EAR. The likelihood of having intake below the EAR was more than five times higher in the NATD $v$. the control group (OR $=5 \cdot 2 ; 95 \%$ CI $1 \cdot 8,15 \cdot 2 ; P<0 \cdot 05)$.

Since these estimates depend on water iodine concentration and we lack concurrent water measurements for 2012-2014, we modelled the following worst- and best-case scenarios. At an assigned water iodine concentration of $1 \mu \mathrm{g} / \mathrm{l}$, representing reliance on desalinated water only, the median estimated intake dropped to $69 \mu \mathrm{g} / \mathrm{d}$ (range $6-263 \mu \mathrm{g} / \mathrm{d}$ ), with mean level of 77 (SD 47) $\mu \mathrm{g} / \mathrm{d}, 93 \%$ of participants with intake below the RDA and $70 \%$ with intake below the EAR (Fig. 1(b)). For the best-case scenario we assigned a value of $170 \mu \mathrm{g} / \mathrm{l}$, representing the maximal concentration ever recorded in drinking-water from a well in Israel. This model estimated a median intake of $139 \mu \mathrm{g} / \mathrm{d}$ (range $10-852 \mu \mathrm{g} / \mathrm{d}$ ), with an overall mean intake of 189 (sD 155) $\mu \mathrm{g} / \mathrm{d}, 53 \%$ participants still exhibiting iodine intake below the RDA and 30\% remaining below the EAR (Fig. 1(c)). Estimated iodine intake was fitted to a two-parameter Weibull distribution (Cramer-von Mises $W$ test, $P>0 \cdot 05)$.

Although water iodine concentration contributed to overall iodine intake, and presumably to the overall risk of deficiency, the mean intake of iodine from drinking-water did not differ between the control and NATD groups (Table 3). However, participants in the NATD group were more than six times less likely to use iodized salt than controls although, given the small sample size, this association was not statistically significant (OR $=0 \cdot 15 ; 95 \%$ CI $0.02,1.32 ; P=0.07)$. The combined consumption of saltwater fish and seafood as well as cow's milk was also significantly lower in NATD participants than in controls (Table 3).

\section{Serum thyroglobulin values}

The results of the serum $\mathrm{Tg}$ measurements revealed a similarly high prevalence of apparent iodine deficiency (Table 3), with an overall median of $21 \mathrm{ng} / \mathrm{ml}$ and a geometric mean of $22.7 \mathrm{ng} / \mathrm{ml}$. Serum Tg was elevated above $10 \mathrm{ng} / \mathrm{ml}$ in $73 \%$ of the overall population and above $40 \mathrm{ng} / \mathrm{ml}$ in $24 \%$, indicating prevalent deficiency ${ }^{(31-34)}$. The geometric mean for serum Tg was higher in the NATD participants compared with controls $(33 v$ v. $17 \mathrm{ng} / \mathrm{ml}$, respectively); however, given the large variance in the NATD group, this difference did not reach statistical significance. The proportion of elevated serum $\mathrm{Tg}$ was similar in NATD participants (76\%) and in controls (78\%). Nevertheless, those in the NATD group were almost six times more likely to have elevated serum Tg above $40 \mathrm{ng} / \mathrm{ml}$ compared with controls (OR $=5 \cdot 8 ; 95 \%$ CI $1 \cdot 6$, 20.8; $P<0.05$; Table 3). Furthermore, linear regression of log-transformed serum Tg $v$. estimated intake showed a significant inverse association between the two $(\beta=-0.250, F=4 \cdot 26, P<0 \cdot 05)$.

\section{Discussion}

In the present study we found evidence of a surprisingly high prevalence of insufficient iodine intake not only in clinically diagnosed cases of NATD but also in euthyroid controls, in a population that is heavily reliant on SWRO desalinated drinking-water. Our study illustrates how the reduction of water iodine by desalination might impact on iodine intake and IDD. Use of the SIFFQ allowed us to model this in our study population. Our findings show that for the habitual intake of food and water, decreasing water iodine concentration from the best-case (well-water only) scenario to the worst-case (desalinated water only) scenario predicts an increase in the prevalence of insufficiency (percentage of the population with intake below the EAR) by as much as $40 \%$. The observed high prevalence of estimated dietary iodine insufficiency was supported by a similarly high prevalence of elevated serum Tg, a putative biomarker for IDD, and by the significant correlation between estimated intake and serum Tg. While we cannot know whether the low overall iodine intake in our study is representative of the general population in Israel, it is internally consistent with the relatively high serum Tg that we observed in our overall population and among controls.

Having carefully excluded other causes of thyroid dysfunction, including autoimmune disease, obesity, use 

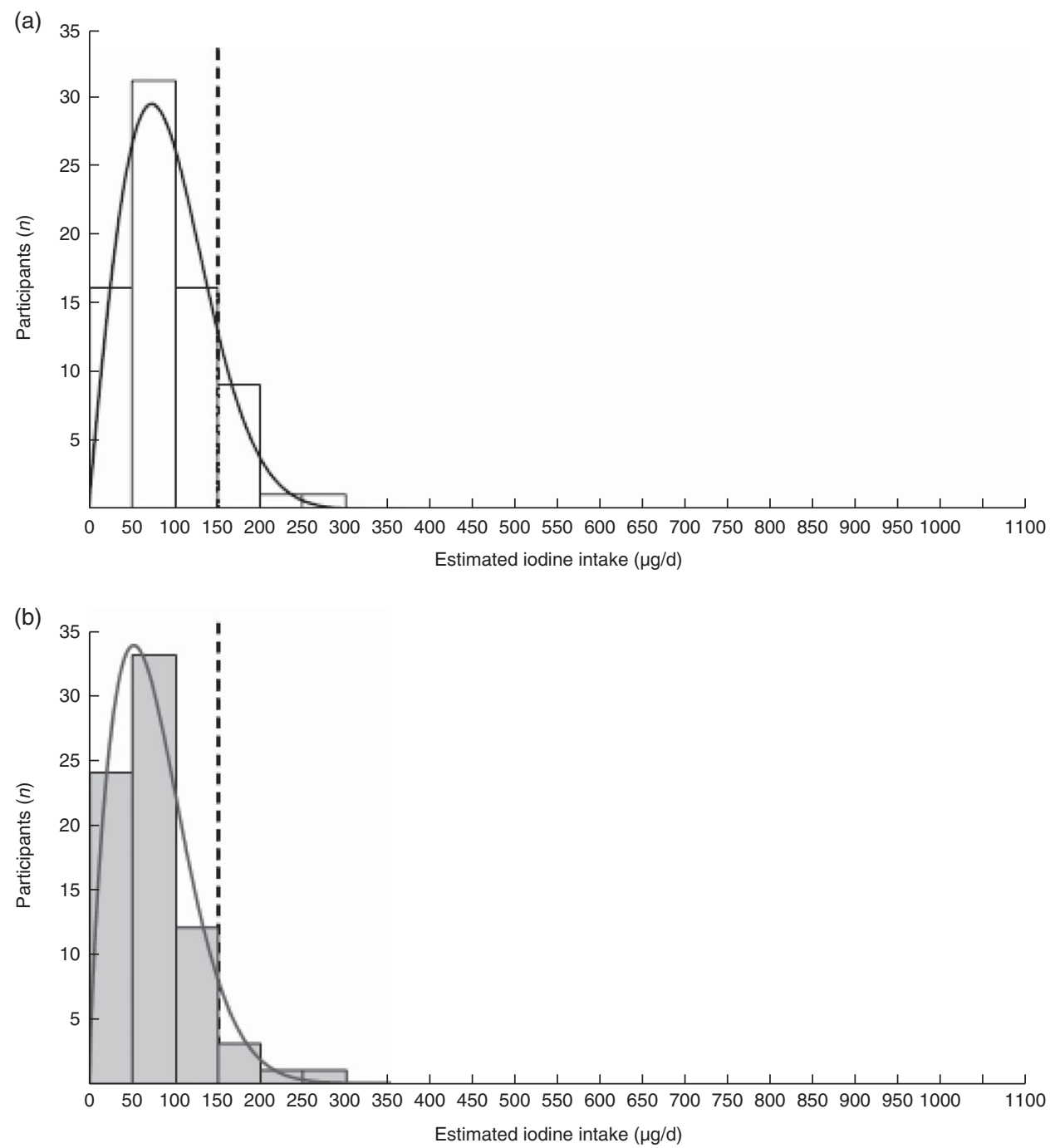

(c)

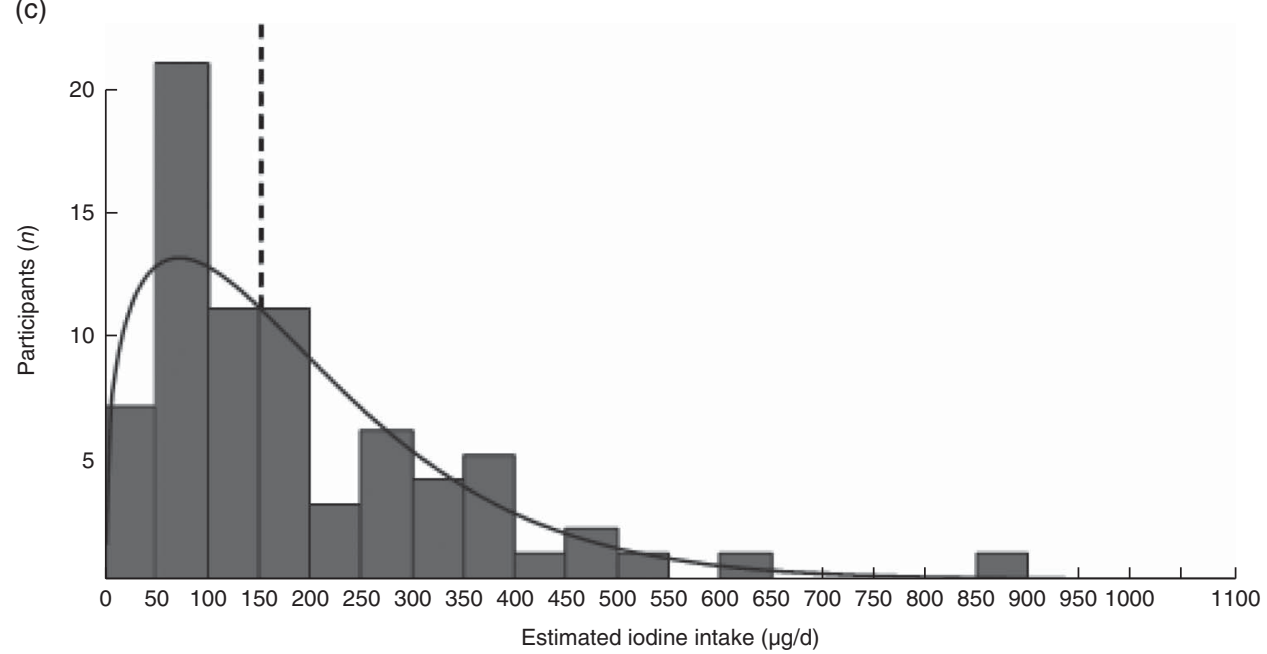

Fig. 1 Models for the distribution of estimated daily iodine intakes according to likely, best- and worst-case assumptions of water iodine content. The distribution of the study population's iodine intake $(\mu \mathrm{g} / \mathrm{d})$ from the sIFFQ $(n$ 74) estimated assuming three different iodine concentrations for tap water: (a) likely, $27 \mu \mathrm{g} / \mathrm{l}$; (b) worst-case scenario using only iodine content in SWRO desalinated water, $1 \mu \mathrm{g} / \mathrm{l}$; (c) best-case scenario based on the highest local iodine content measured in well water, $170 \mu \mathrm{g} / \mathrm{l}$. - indicates Weibull fit; - _ - - indicates RDA reference line $(150 \mu \mathrm{g} / \mathrm{d})$ (sIFFQ, semi-quantitative iodine FFQ; SWRO, seawater reverse osmosis) 
Table 3 Estimated daily dietary iodine intake, estimated unfiltered tap water intake, dietary habits and serum Tg of controls $v$. NATD in the study population of volunteers aged 21-80 years, Ashkelon, Israel, March 2012-March 2014

\begin{tabular}{|c|c|c|c|c|c|c|c|}
\hline \multirow[b]{2}{*}{ Characteristic } & \multicolumn{2}{|c|}{ Control } & \multicolumn{2}{|c|}{ NATD } & \multirow[b]{2}{*}{$P$} & \multirow[b]{2}{*}{ OR } & \multirow[b]{2}{*}{$95 \% \mathrm{Cl}$} \\
\hline & Mean or $n$ & SD or $\%$ & Mean or $n$ & SD or $\%$ & & & \\
\hline$n$ & \multicolumn{2}{|c|}{37} & \multicolumn{2}{|c|}{29} & & & \\
\hline Estimated daily dietary iodine intake $(\mu \mathrm{g} / \mathrm{d})^{\star}$ & $112 \cdot 6$ & $56 \cdot 8$ & 71.9 & 34.8 & $<0.05$ & & \\
\hline lodine intake $<$ RDA, $n$ and \%† & 28 & 76 & 28 & 97 & $<0.05$ & $9 \cdot 0$ & $1 \cdot 1,75 \cdot 8$ \\
\hline lodine intake $<\mathrm{EAR}, n$ and $\% \dagger$ & 8 & 27 & 22 & 73 & $<0.05$ & $5 \cdot 2$ & $1 \cdot 8,15 \cdot 2$ \\
\hline Mean unfiltered tap water intake (litres/d) & \multicolumn{2}{|c|}{0.8} & \multicolumn{2}{|c|}{0.5} & NS & & \\
\hline $\begin{array}{l}\text { Unfiltered tap water consumption, } n \text { and } \% \\
\text { lodine intake }(\mu \mathrm{g} / \mathrm{d})\end{array}$ & 25 & 68 & 21 & 72 & NS & & \\
\hline From unfiltered tap water $\ddagger$ & \multicolumn{2}{|c|}{21.6} & \multicolumn{2}{|c|}{14.4} & NS & & \\
\hline From saltwater fish and seafood§ & \multicolumn{2}{|c|}{21.0} & \multicolumn{2}{|c|}{$10 \cdot 1$} & $<0.05$ & & \\
\hline From cow's milk* & \multicolumn{2}{|c|}{$17 \cdot 8$} & \multicolumn{2}{|c|}{11.8} & $<0.05$ & & \\
\hline From cow's yogurt & \multicolumn{2}{|c|}{$18 \cdot 9$} & \multicolumn{2}{|c|}{$14 \cdot 8$} & NS & & \\
\hline From eggs & \multicolumn{2}{|c|}{$9 \cdot 6$} & \multicolumn{2}{|c|}{7.5} & NS & & \\
\hline Past or current seafood consumption, $n$ and $\%$ & 8 & 22 & 4 & 14 & NS & & \\
\hline Past or current seaweed consumption, $n$ and $\%$ & 5 & 13 & 2 & 7 & NS & & \\
\hline lodized salt use, $n$ and \%ll & 7 & 19 & 1 & 3 & 0.07 & 0.15 & $0.02,1.32$ \\
\hline Intake of an iodine-containing dietary supplement, $n$ and \% & 1 & 3 & 0 & 0 & NS & & \\
\hline Mean serum $\mathrm{Tg}(\mathrm{ng} / \mathrm{ml}) \boldsymbol{\uparrow}$ & \multicolumn{2}{|c|}{$17 \cdot 0$} & \multicolumn{2}{|c|}{33.0} & 0.08 & & \\
\hline Elevated serum Tg, $n$ and \%† & 29 & 78 & 22 & 76 & NS & & \\
\hline Abnormal elevated serum $\mathrm{Tg}, n$ and \%† & 4 & 11 & 12 & 41 & $<0.05$ & $5 \cdot 8$ & $1 \cdot 6,20 \cdot 8$ \\
\hline Mean serum TSH (mlU/l) & $1 \cdot 8$ & 1.0 & 1.9 & $1 \cdot 2$ & NS & & \\
\hline
\end{tabular}

NATD, non-autoimmune thyroid disease; EAR, Estimated Average Requirement; Tg, thyroglobulin; TSH, thyrotropin.

$\mathrm{RDA}=150 \mu \mathrm{g} / \mathrm{d} ; \mathrm{EAR}=95 \mu \mathrm{g} / \mathrm{d}$; elevated serum $=\mathrm{Tg} \geq 10 \mathrm{ng} / \mathrm{ml}$; abnormal elevated serum $\mathrm{Tg}=\mathrm{serum} \mathrm{Tg}>40 \mathrm{ng} / \mathrm{ml}$.

*Significant difference (Welch ANOVA test, $a=0.05$ ).

†Significant difference (Fisher's exact test, $a=0.05$ ).

łlodine content in tap water was considered $27 \mu \mathrm{g} / \mathrm{l}$.

$\S$ Significant difference (Kruskal-Wallis test, $a=0.05$ ).

Illodized salt $=3 \mu \mathrm{g}$ iodine $/ 100 \mathrm{~g}$.

\Geometric mean.

of iodine-containing or steroidal drugs, cancer and pregnancy, the finding of inadequate iodine intake implicates iodine deficiency in the NATD group as a likely cause or contributor to the observed disease. Although we cannot rule out other causes with certainty, it is noteworthy that these patients reside in a location where the primary source of drinking-water is derived from iodine-poor SWRO desalinated water ${ }^{(14,20,23,27)}$. Non-toxic hypothyroidism is often observed in areas with iodine deficiency, and higher rates of both subclinical and overt hyperthyroidism have been observed in areas with no salt iodization $^{(1,5)}$. Thus it is likely that the diagnosis of NATD is a manifestation of IDD.

With respect to Israel, our findings substantially challenge the decades-old assumption that Israel is an iodine-sufficient country due to its proximity to the Mediterranean $^{(37,38)}$. Our finding of apparent iodine deficiency (serum $\mathrm{Tg} \geq 10 \mu \mathrm{IU} / \mathrm{ml})^{(31,32)}$ among $73 \%$ of the current sample is relatively higher than the finding of a similarly limited study of subjects in a hospital situated near the Mediterranean coast, in the Tel-Aviv metropolitan area, which was published a decade ago by Benbassat et al. ${ }^{(39)}$. In that study the prevalence of iodine deficiency was estimated to be about $35 \%$ when intake was assessed by urinary iodine concentration ${ }^{(39)}$. Unlike Benbassat and colleagues, we excluded volunteers whose diagnosis of thyroid disease predated the use of desalinated water. Although both these studies are small, the apparent increase in deficiency in the intervening years supports the possibility of a trend of increased IDD in the population related to a parallel trend in wide-scale use of SWRO desalinated water as a major source of drinking and irrigation water in Israel ${ }^{(13-17)}$, including the Ashkelon District $^{(20-22)}$.

We observed substantially lower iodine intake and higher serum $\mathrm{Tg}$ in our control group than those found in euthyroid adults in comparable hospital-based studies of iodine intake status in other countries. For example, in a study conducted in Skagen, Denmark, located on the North Sea coast, a median serum $\mathrm{Tg}$ of $7 \cdot 7 \mu \mathrm{g} / \mathrm{l}$ was observed among controls with elevated values (defined as serum $\mathrm{Tg}>20 \mathrm{ng} / \mathrm{dl}$ ) among $21 \%$ of the group ${ }^{(40)}(n$ 96, median age $=76$ years, men/women $51 / 45$, mean unfiltered tap water intake per person $=1.6$ litres $/ \mathrm{d}$ ) (S Andersen, Head of Department of Geriatric and Internal Medicine, Aalborg University Hospital, Denmark, personal communication, 27 July 2014). The discrepancy between the data from Ashkelon and Skagen can be explained by an elevenfold higher iodine intake from water in Skagen compared with Ashkelon, based on water iodine content and consumption of water in the two studies $(140 \mu \mathrm{g} / \mathrm{l}$ $\times 1.6$ litres $/ \mathrm{d} v .27 \mu \mathrm{g} / 1 \times 0.7$ litres $/ \mathrm{d}$, respectively $)^{(23,40)}$. A similar small hospital-based survey in Jeddah, Saudi Arabia ( $n$ 53, median age $=37$ years, men/women 4/49) reported a median estimated iodine intake of $195 \mu \mathrm{g} / \mathrm{d}$ and median serum $\mathrm{Tg}$ of $4.27 \mathrm{ng} / \mathrm{dl}$, and only $19 \%$ of the group 
had iodine insufficiency values (serum $\mathrm{Tg} \geq 10 \mathrm{ng} / \mathrm{dl})^{(30)}$. Jeddah is located on the coast of the Red Sea where SWRO desalination is also extensively used. However, in contrast to Israel, salt in Saudi Arabia is iodized and saltwater fish consumption in Jeddah is high ${ }^{(30)}$, which likely reduced the relative contribution of drinking-water to total iodine intake $^{(41,42)}$. Both studies used hospital populations and samples sizes comparable to our own, but in addition to $\mathrm{Tg}$ they also measured urinary iodine concentration.

Although our findings demonstrate that low water iodine concentration can limit iodine intake in the overall population, water consumption did not differ between NATD (probable IDD) participants and controls. We therefore examined what other sources of dietary iodine intake, in addition to water, might distinguish between the control and NATD groups to increase the risk of IDD. Dairy products, fish and bread are thought to contribute significantly to iodine intake elsewhere ${ }^{(43-45)}$. Of these, we found that the consumption of iodized salt, saltwater fish and seafood, and cow's milk was lower among NATD participants than among controls (Table 3). Notably, Israel has no national programme of universal salt iodization ${ }^{(24)}$ nor is there routine monitoring of iodine intake ${ }^{(25)}$. These findings, that voluntary consumption of iodized salt considerably decreased the likelihood of thyroid disease in the context of prevalent inadequate intake, underscore the need to monitor iodine intake and consider universal salt iodization for Israel.

The study has a number of limitations. First, its design does not allow us to show a temporal association between increased desalination and increased risk of IDD. Since Israel has no national survey data or routine monitoring of these conditions ${ }^{(25)}$, the present study is the first attempt to explore these important questions. Because it was not feasible to limit the study to participants with incident thyroid disease we allowed the inclusion of volunteers who had received a diagnosis of thyroid disease up to 5 years before the study ${ }^{(27)}$, with additional strictly applied inclusion criteria. Although it is possible that a diagnosis of thyroid disease could lead to a change of diet to include more iodine-rich foods, the observation of significantly lower iodine intake among NATD patients with probable IDD makes this potential bias unlikely. Second, we assessed iodine intake and status indirectly by SIFFQ and serum $\mathrm{Tg}$, rather than by urinary iodine concentration. While urinary iodine concentration is commonly used in population studies ${ }^{(2-4,39)}$, we did not use it here because urinary iodine concentration indicates only recent iodine intake (days), whereas IDD and hypothyroidism develop following long-term (years) inadequate iodine intake ${ }^{(5,32)}$. We therefore chose to complement the sIFFQ, which classifies habitual intake and dietary patterns in the long term (up to 1 year) ${ }^{(29,32)}$, with serum Tg, which is thought to reflect intermediate iodine intake over recent months ${ }^{(32)}$. Third, it was a relatively small hospital-based study with a single geographic catchment area. While we could model the contribution of water to iodine intake and NATD under certain assumptions, the lack of variance in the water supply did not allow us to compare iodine deficiency in populations with greater and lesser exposure to desalinated water.

Despite these limitations, our observations are consistent with the hypothesis that SWRO desalination can significantly affect the iodine intake of reliant populations. If true, this could have far-reaching public health implications for the growing number of people around the world whose fresh water supply derives from desalinated water.

Although based on a very small convenience sample but also because of this - the study underscores the urgent need for reliable national data in Israel to illuminate trends of increasing iodine deficiency and thyroid disease in the context of iodine-depleted desalinated drinking-water. A nationally representative survey of school-aged children, and a parallel ecological survey of iodine concentration in drinking-water along the same sampling frame, would provide critical information on the extent of iodine deficiency and its relationship to iodine water content in Israel. Moreover, it would constitute a first, long overdue step towards routine monitoring of IDD and instituting iodine prophylaxis, whether through universal salt iodization $^{(4,25)}$ or by directly replacing iodine in the water, as previously suggested for other minerals ${ }^{(16,46)}$. The data from such a survey would also prove invaluable to groups seeking to improve the health of populations in other areas of the world where increasing dependence on SWRO desalination for water may be putting the welfare of the populations at risk.

\section{Acknowledgements}

Acknowledgements: The authors are indebted to the participating patients at BUMCA who volunteered for this study; to Dr Inbar Zucker from ICDC for her assistance with the background data regarding thyroid disease in Israel; to Mr Yuri Kasperuk, Israel's Southern Region Water Supply Engineer at Mekorot Israel National Water Co., for information regarding the proportion of desalinated water supplied to specific municipalities; to Mrs Irit Hen, Drinking Water National Engineer of the Environment Health Department at the Ministry of Health, for information regarding iodide concentration of drinking-water in Israel; to Professor Avigdor Cahaner from the Institute of Plant Sciences and Genetics in Agriculture at The Hebrew University for assistance with the statistical analysis; and to Mrs Nirit Nagar from the Department of Internal Medicine ' $\mathrm{C}$ ' at BUMCA for assistance with the internal administration at BUMCA. Financial support: This research received no specific grant from any funding agency in the public, commercial or not-for-profit sectors. Conflict of interest: None. Authorship: Y.S.O., D.G. and A.M.T. conceived of 
and designed the study; D.G., Y.S.O. and S.T. recruited participants and obtained informed consent; Y.S.O. administered the dietary interviews and questionnaires; Y.S.O., D.G., D.A., S.T. and S.F. collected the data; Y.S.O., D.G. and A.M.T. analysed the data; Y.S.O., D.G. and A.M.T., drafted the manuscript; all authors approved the final manuscript. Ethics of human subject participation: This study was conducted according to the guidelines laid down in the Declaration of Helsinki and all procedures involving human patients were approved by the BUMCA ethics committee. Written informed consent was obtained from all patients.

\section{Supplementary material}

To view supplementary material for this article, please visit http://dx.doi.org/10.1017/S1368980016000951

\section{References}

1. Zimmermann MB, Jooste PL \& Pandav CS (2008) Iodinedeficiency disorders. Lancet 372, 1251-1262.

2. Michalaki M, Kyriazopoulou V, Paraskevopoulou $\mathrm{P}$ et al. (2008) The odyssey of nontoxic nodular goiter (NTNG) in Greece under suppression therapy, and after improvement of iodine deficiency. Thyroid 18, 641-645.

3. Aghini Lombardi E, Fiore M, Tonacchera L et al. (2013) The effect of voluntary iodine prophylaxis in a small rural community: the Pescopagano survey 15 years later. $J$ Clin Endocrinol Metab 98, 1031-1039.

4. World Health Organization, UNICEF \& International Council for Control of Iodine Deficiency Disorders (2007) Assessment of Iodine Deficiency Disorders and Monitoring Their Elimination: A Guide for Programme Managers, 3rd ed. Geneva: WHO.

5. Zimmermann MB \& Boelaert K (2015) Iodine deficiency and thyroid disorders. Lancet Diabetes Endocrinol 3, 286-295.

6. Bahn RS \& Castro MR (2011) Approach to the patient with nontoxic multinodular goiter. J Clin Endocrinol Metab 96, 1202-1212.

7. Zimmermann MB, Hess SY, Adou P et al. (2003) Thyroid size and goiter prevalence after introduction of iodized salt: a 5-y prospective study in schoolchildren in Cote d'Ivoire. Am J Clin Nutr 77, 663-667.

8. Rosenthal E \& Mates A (1986) Iodine concentrations in groundwater of northern Israel and their relation to the occurrence of goiter. Appl Geochem 1, 591-600.

9. Madar L, Hen I \& Goldberger S (2003) Iodide content in Israel drinking water sources survey. In Environmental Health Report (Bri'ut u'Sviva), pp. 7-10. Jerusalem: Israel Ministry of Health, Department of Environmental Health (in Hebrew).

10. Miller DD \& Welch RM (2013) Food system strategies for preventing micronutrient malnutrition. ESA Working Paper no. 13.06, Agricultural Development Economics Division, FAO. http://www.fao.org/fileadmin/templates/esa/Papers_ and_documents/WP_13_06_Miller_Welch.pdf (accessed March 2015).

11. Schiermeier Q (2008) Water: purification with a pinch of salt. Nature 452, 260-261.

12. International Desalination Association (2015) Desalination by the numbers. http://idadesal.org/desalination-101/ desalination-by-the-numbers/ (accessed March 2015).
13. Ovadia YS, Troen AM \& Gefel D (2013) Seawater desalination and iodine deficiency: is there a link? IDD Newsl 3, 13-14.

14. Rejwan A (editor) (2011) The Israeli Water Authority National Water Efficiency Report. http://www.water.gov.il/ Hebrew/ProfessionalInfoAndData/2012/04-The-State-ofIsrael-National-Water-Efficiency-Report.pdf (accessed November 2014).

15. Feitelson E \& Rosenthal G (2012) Desalination, space and power: the ramifications of Israel's changing water geography. Geoforum 43, 272-284.

16. Yermiyahu U, Tal A, Ben-Gal A et al. (2007) Environmental science. Rethinking desalinated water quality and agriculture. Science 318, 920-921.

17. Lahav O, Kochva M \& Tarchitzky J (2010) Potential drawbacks associated with agricultural irrigation with treated wastewaters from desalinated water origin and possible remedies. Water Sci Technol 61, 2451-2460.

18. Azenkot A (2012) Water and irrigation. In Israel's Agriculture Booklet, pp. 18-19 [A Regev, S Moisa and Y Kiriati, editors]. Tel-Aviv: Israel Export and International Cooperation Institute; available at http://www.moag.gov.il/agri/ files/Israel's_Agriculture_Booklet.pdf

19. Gabelich CJ, Williams MD, Rahardianto A et al. (2007) Highrecovery reverse osmosis desalination using intermediate chemical demineralization. J Membr Sci 301, 131-141.

20. Gefel D, Turkot S, Aharoni D et al. (2016) Serum thyroglobulin levels and estimated iodine intake in adults exposed to iodine-diluted desalinated drinking water (pilot study). Harefuah (In the Press, in Hebrew).

21. Sauvet-Goichon B (2007) Ashkelon desalination plant - a successful challenge. Desalination 203, 75-81.

22. Farkash E \& Eliyahu N (2010) Drain project in eastern South Beach Aquifer restoration - Lahat desalination plant. Mekorot Ba'Shetach - Southern Region 5, 1 (in Hebrew); available at http://www.magazine-pro.com/13/45/A/390/ Mekorot

23. State of Israel, Ministry of Health, Department of Health and Environment, Drinking Water Unit (2008) Survey of Iodide Levels of Drinking Water in the Ashkelon District. Jerusalem: Israel Ministry of Health.

24. Leventhal A, Arbel N \& Ginsberg A (2008) The fortification of salt with iodine worldwide and its implication in Israel. Harefuah 147, 241-246, 277 (in Hebrew).

25. Andersson M \& Zimmermann MB (2012) Global iodine nutrition: a remarkable leap forward in the past decade. IDD Newsl 40, 1-5.

26. Valavala R, Sohn J, Han J et al. (2011) Pretreatment in reverse osmosis seawater desalination: a short review. Environ Eng Res 16, 205-212.

27. Ovadia YS, Gefel D, Turkot S et al. (2014) Elevated serum thyroglobulin and low iodine intake are associated with non-toxic nodular goiter among adults living near the eastern Mediterranean coast. J Thyroid Res 2014, 913672.

28. Valeix P, Faure P, Bertrais S et al. (2008) Effects of light to moderate alcohol consumption on thyroid volume and thyroid function. Clin Endocrinol (Oxf) 68, 988-995.

29. Rasmussen LB, Ovesen L, Bülow I et al. (2001) Evaluation of a semi-quantitative food frequency questionnaire to estimate iodine intake. Eur J Clin Nutr 55, 287-292.

30. Alissa EM, Al Shali K \& Ferns GA (2009) Iodine deficiency among hypothyroid patients living in Jeddah. Biol Trace Elem Res 130, 193-203.

31. Knudsen N, Bulow I, Jorgensen T et al. (2001) Serum Tg: a sensitive marker of thyroid abnormalities and iodine deficiency in epidemiological studies. J Clin Endocrinol Metab 86, 3599-3603.

32. Zimmermann MB \& Andersson M (2012) Assessment of iodine nutrition in populations: past, present, and future. Nutr Rev 70, 553-570. 
33. Ma ZF \& Skeaff SA (2014) Thyroglobulin as a biomarker of iodine deficiency: a review. Thyroid 24, 1195-1209.

34. Giovanella L, Imperiali M, Ferrari A et al. (2012) Serum thyroglobulin reference values according to NACB criteria in healthy participants with normal thyroid ultrasound. Clin Chem Lab Med 50, 891-893.

35. Demers LM \& Spencer CA (2003) National Academy of Clinical Biochemistry 2002 Laboratory support for the diagnosis and monitoring of thyroid disease. Thyroid 13, 3-126.

36. Food and Nutrition Board, Institute of Medicine (2001) Iodine. In Dietary Reference Intakes for Vitamin A, Vitamin K, Arsenic, Boron, Chromium, Copper, Iodine, Iron, Manganese, Molybdenum, Nickel, Silicon, Vanadium, and Zinc, pp. 258-289. Washington, DC: National Academy Press.

37. Zohar Y (1994) Endemic goiter in a non-goitrogenic country. Harefuah 127, 75-78 (in Hebrew).

38. Lubina A, Cohen O, Barchana $\mathrm{M}$ et al. (2006) Time trends of incidence rates of thyroid cancer in Israel: what might explain the sharp increase. Thyroid 16, 1033-1040.

39. Benbassat C, Tsvetov G, Schindel B et al. (2004) Assessment of iodine intake in the Israel coastal area. Isr Med Assoc J 6, $75-77$.
40. Andersen S, Iversen F, Terpling S et al. (2009) More hypothyroidism and less hyperthyroidism with sufficient iodine nutrition compared to mild iodine deficiency-a comparative population-based study of older people. Maturitas 64 , 126-131.

41. Kassim IA, Moloney G, Busili A et al. (2014) Iodine intake in Somalia is excessive and associated with the source of household drinking water. J Nutr 144, 375-381.

42. Henjum S, Barikmo I, Strand TA et al. (2012) Iodine-induced goitre and high prevalence of anaemia among Saharawi refugee women. Public Health Nutr 15, 1512-1518.

43. Li M, Waite KV, Ma G et al. (2006) Declining iodine content of milk and re-emergence of iodine deficiency in Australia. Med J Aust 184, 307.

44. Dahl L, Johansson L, Julshamn K et al. (2004) The iodine content of Norwegian foods and diets. Public Health Nutr $\mathbf{7}$, 569-576.

45. Pearce EN, Pino S, He X et al. (2004) Sources of dietary iodine: bread, cows' milk, and infant formula in the Boston area. J Clin Endocrinol Metab 89, 3421-3424.

46. Spungen JH, Goldsmith R, Stahl Z et al. (2013) Desalination of water: nutritional considerations. Isr Med Assoc J 15, $164-168$ 